\title{
FUNGSI POSISI PADA ROBOT SEPAK BOLA UPN “VETERAN" YOGYAKARTA
}

\author{
Awang Hendrianto Pratomo, Bambang Yuwono dan Nursyam Majid \\ Teknik Informatika Universitas Pembangunan Nasional "Veteran" Yogyakarta \\ Jl. Babarsari No. 2 Tambak bayan, Yogyakarta \\ e-mail : awang@upnyk.ac.id
}

\begin{abstract}
Position function on the robot system MiroSot is the basic of the robot ability is used controlled the robot movement, to controlled the robot be able to move into the desired position. The position function of robot soccer UPN "Veteran" Yogyakarta is using by the position functions was developed by Prof. Kim. The position functions are not suitable with the characteristics of the robot MiroSot UPN "Veteran" Yogyakarta. The robot movement is not suitable, slow and can not stopped when it reached the position. It is caused by the position function is used have speed and control parameters using proportional control PID (Proportional Integral Derifative). PID parameters are used not suitable with the character of the robot.function. The results of the function test, the robot position function without a gyroscope sensor has a maximum speed of with distance more than $100 \mathrm{~cm}$, with a maximum speed are $70 \mathrm{~cm} / \mathrm{s}$, is greater when compared with positioning function developed by Kim at $55 \mathrm{~cm} / \mathrm{s}$. while the position function are using gyroscope sensor has a maximum speed of the error distance of more than $100 \mathrm{~cm}$, with maximum speed of $120 \mathrm{~cm} / \mathrm{s}$, is greater when compared with the position function developed by Kim and position functions without using a gyroscope sensor.
\end{abstract}

Keywords : Position Function, MiroSot, Robot Soccer, Gyroscope Sensor

\begin{abstract}
Abstrak
Fungsi posisi Pada sistem robot MiroSot merupakan kemampuan dasar robot yang digunakan untuk menggerakkan robot agar dapat menuju ke posisi yang diinginkan. Fungsi posisi dalam robot sepak bola UPN "Veteran" Yogyakarta masih menggunakan fungsi yang dikembangkan oleh Prof Kim. Fungsi didalam strategi tersebut tidak sesuai dengan karakter dari robot MiroSot UPN "Veteran" Yogyakarta. Pergerakan yang dihasilkan tidak tetap, lambat dan tidak dapat berhenti ketika sudah sampai di posisi dituju. Hal ini dikarenakan fungsi posisi yang digunakan mempunyai parameter kecepatan dan kontrol kendali proportional dari PID (Proportional Integral Derifative). Parameter PID yang digunakan tidak sesuai dengan karakter dari dari robot.Fungsi yang digunakan. Hasil pengujian fungsi posisi tanpa menggunakan sensor gyroscope mempunyai kecepatan maksimal pada eror jarak lebih dari $100 \mathrm{~cm}$, yaitu dengan kecepatan $70 \mathrm{~cm} / \mathrm{s}$, lebih besar jika dibandingkan dengan fungsi positioning yang dikembangkan oleh Kim yaitu $55 \mathrm{~cm} / \mathrm{s}$. sedangkan fungsi posisi dengan menggunakan sensor gyroscope mempunyai kecepatan maksimal pada eror jarak lebih dari $100 \mathrm{~cm}$, yaitu pada kecepatan $120 \mathrm{~cm} / \mathrm{s}$, lebih besar jika dibandingkan dengan fungsi posisi yang dikembangkan oleh Kim dan fungsi posisi tanpa menggunakan sensor gyroscope.
\end{abstract}

Kata Kunci : Fungsi Posisi, MiroSot, Robot Sepak Bola, Sensor Gyroscope

\section{PENDAHULUAN}

MiroSot merupakan kategori pertandingan robot sepak bola dengan setiap timnya ada yang berjumlah tiga robot, lima robot dan sebelas robot (Han et al., 2002). Aturan yang digunakan untuk ukuran robot MiroSot adalah robot memiliki dimensi tidak boleh lebih besar dari 7,5 x 7,5 x 7,5 $\mathrm{cm}^{3}$ (Han et al., 2002; Simancas, 2004). Untuk menggerakan robot dalam sebuh pertandingan dibutuhkan sebuah strategi (Han et al., 2002). Sebagian besar pengolahan strategi dilakukan dalam PC dan perintah dikirim melalui gelombang radio, bluetooth atau WiFi (Simancas, 2004). Fungsi dasar pergerakan robot yang digunakan agar robot dapat menuju ke posisi yang diinginkan adalah fungsi posisi. Fungsi posisi yang digunakan masih menggunakan fungsi posisi yang dikembangkan oleh Prof Kim et al. Oleh karena itu pergerakan robot untuk menuju posisi tujuan masih banyak over shoot, lambat, dan tidak dapat berhenti ketika sampai 
pada posisi yang diinginkan. Masalah tersebut disebabkan karena fungsi posisi yang digunakan tidak cocok dengan karakter dari robot MiroSot UPN "Veteran" Yogyakarta.

Penelitian ini membahas mengenai fungsi posisi yang digunakan untuk robot MiroSot UPN "Veteran" Yogyakarta. Agar robot dapat bergerak dengan lintasan terpendek sehingga memperkecil over shoot.Dibutuhkan kendali kecepatan robot, pergerakan angular yang diatur menggunakan sensor gyroscope dan radius toleransi minimal dicari agar robot dapat langsung berhenti ketika sampai pada posisi tujuan. Tujuan dari penelitian ini adalah untuk membuat fungsi posisi yang sesuai dengan karakter robot.

\subsection{Robot MiroSot}

Robot MiroSot adalah salah satu kategori permainan robot sepakbola internasional yang dinaungi oleh FIRA. Untuk membangun sistem permainan mirosot dibutuhkan kombinasi kontrol motor, vision system, dan komunikasi. (Simancas, 2004; Huabin et al, 2004). Ukuran dari robot mirosot adalah $7,5 \times 7,5 \times 7,5 \mathrm{~cm}$. Lapangan pertandingan mempunyai ukuran $220 \times 180 \mathrm{~cm}$, dengan warna hitam dan garis batas putih (FIRA, 2014), seperti ditunjukkan dalam Gambar 1.

\subsubsection{Sistem Visi}

Sistem visi merupakan sarana untuk mendapatkan informasi letak dari robot dan bola di lapangan. Untuk mendeteksi robot diperlukan patch dengan berbagai perpaduan warna. Warna patch terdiri dari kombinasi berbagai warna, hal tersebut digunakan untuk mendefinisikan tim dan nomor id robot (Han et al., 2004; Choi et al., 2009).Alat untuk mengambil visi ini menggunakan kamera digital dengan resolusi HD (High Definition) yang diletakkan di atas lapangan (Gang et al., 2010). Kamera yang digunakan mempunyai kecepatan pengambilan gambar lebih dari 55 frame per detik (Gang et al., 2010).Sebuah sistem visi agar dapat memperoleh sebuah informasi gambar dibutuhkan proses perhitungan dan pengolahan citra yang dikenal dengan kalibrasi kamera (Wang et al., 2010).Kalibrasi kamera bertujuan untuk mendeteksi koordinat yang ada di lapangan dengan kamera (Guerchouche dan Coldefy, 2007). Di dalam kalibrasi kamera kebanyakan menggunakan metode yang didasari pengolahan citra dan rekonstruksi 3D (Guerchouche dan Coldefy, 2007). Setelah mengkalibrasi kamera maka terbentuklah koordinat sesuaikan keadaan lapangan, kemudian informasi akan dimunculkan pada aplikasi yang ada di komputer (Guerchouche dan Coldefy, 2007

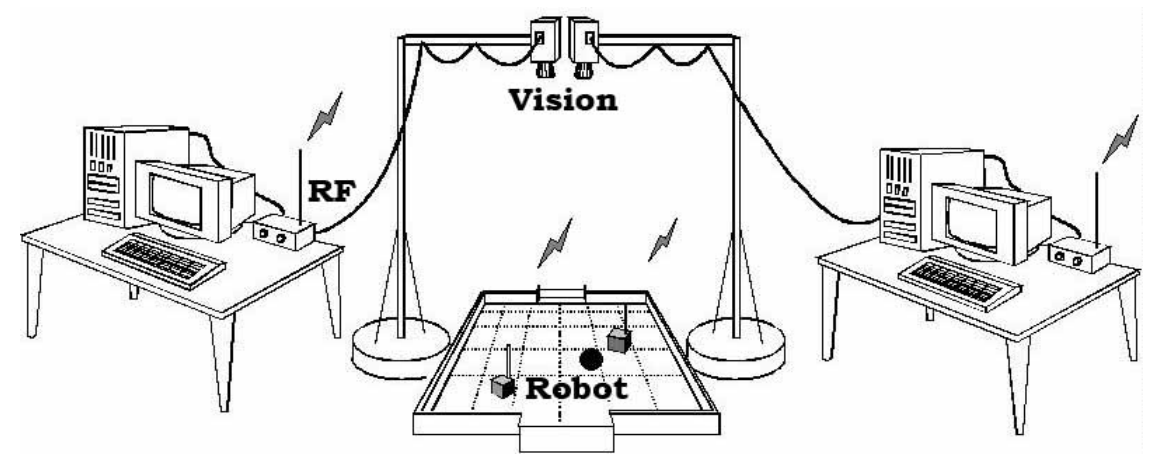

\section{Gambar 1 Sistem Mirosot}

) .

\subsubsection{Sistem Komunikasi}

Sistem komunikasi digunakan untuk menghubungkan komputer dengan robot. Sistem komunikasi yang diperbolehkan oleh FIRA untuk pertandingan MiroSot adalah sistem komunikasi nirkabel (Kim et al., 1997).Radio Frequency (RF) merupakan salah satu pilihan yang tepat untuk sistem komunikasi robot sepak bola karena gelombang ini dapat digunakan untuk komunikasi jarak jauh dan tidak ada hambatan komunikasi antara host komputer dan robot, dan juga mendukung multi-channel (Li et al., 2004; Vieira et al., 2001).Sistem komunikasi yang ada pada robot terdiri dari modul radio receiver, transmiter dan mikrokontroler (Vieira et al., 2001). Setelah menerima data, selanjutnya mikrokontroler akanmemverifikasi data (Vieira et al., 2001). 


\subsubsection{Sensor Gyroscope}

Gyroscope merupakan sensor fisik yang digunakan untuk mendeteksi dan mengukur kecepatan sudut dari suatu objek (Trusov, 2011). Berdasarkan kegunaannya sesnsor gyroscope dibagi menjadi dua ketegori yaitu untuk mengukur kecepatan sudut atau mendeteksi sudut dan untuk mengukur perputaran rata-rata dari suatu objek (Trusov, 2011). Dengan menggunakan gyroscope kategori angle gyroscope dapat didapatkan posisi sudut atau orientasi dari objek secara langsung (Trusov, 2011).Robot MiRoSoT menggunakan sensor Gyroscope dan sensor Accelerometer yang dibuat oleh InvenSense dengan seri MPU-6050 (Baltes, et al., 2004).

\subsection{Strategi}

Strategi pada robot sepak bola merupakan sekumplan algoritma untuk menggerakkan robot secara kelompok sehingga robot dapat mencetak gol ke gawang lawan sebanyak mungkin. Berdasarkan posisi bola di dalam pertandingan robot MiroSot strategi terdiri dari strategi bertahan dan menyerang. (Benhabib, 2008; Pana et al., 2008).Ketika bertahan sebuah tim memerluakan kerjasama agar bola tidak dapat masuk ke gawang sendiri, baik itu kerjasama dalam memblok datangnya bola atau merebut bola (Pana et al., 2008). Ketika keadaan menyerang dibutuhkan fungsi untuk menggiring bola, sehingga diperoleh sebanyak mungkin kesempatan agar bola dapat di tembak masuk ke gawang lawan (Pana et al., 2008).

\subsection{Kemampuan Dasar Robot}

Kemampuan dasar robot merupakan dasar dari pergerakan robot, baik berupa bergerak, menghadap ke sebuah sudut ataupun menuju ke titik yang sudah ditentukan. Fungsi posisi merupakan gabungan antara fungsi velocity dan fungsi turning yang diperuntukkan menuju ke sebuah tempat dalam suatu bidang. Untuk mengkontrol pergerakan dibutuhkan kontrol kendali proportional dari PID (Proporsional, Integral dan Derifativ) (Miranda, 2009). Fungsi dasar pada umumnya menggerakkan robot berdasarkan selisih sudut antara robot dengan posisi tujuan (Kim et al., 2004). Dengan menggunakan selisih sudut maka pergerakan angular (belok) dan linear (lurus) dapat terbentuk berdasarkan posisi tujuan (Kim et al., 2004).

\section{METODE PENELITIAN}

\subsection{Flowchart Fungsi Posisi Satu Muka}

Robot akan menuju ke posisi tujuan dengan dengan satu muka kebanyakan digunakan dalam strategi menyerang, misalnya dalam keadaan membawa bola atau melakukan fungsi menghindari halangan. Ketika robot di perintahkan untuk menuju ke posisi tertentu maka diperlukan deteksi koordinat robot, hal ini sudah di atur di dalam sistem visi. Selain membutuhkan deteksi koordinat diperlukan juga deteksi sudut agar robot dapat menuju ke posisi tujuan dengan efisien, fungsi pendeteksi sudut juga telah di atur di sistem visi. Fungsi posisi yang di bangun akan membuat robot berhenti ketika telah sampai di posisi tujuan. Flowchart fungsi posisi satu muka dapat dilihat pada Gambar 2. Pada saat perintah diberikan pada robot untuk berhenti maka velocity $=0$. Ketika robot pergi kebola maka velocity akan disesuaikan dengan jarak dan sudut dari posisi tujuan. 


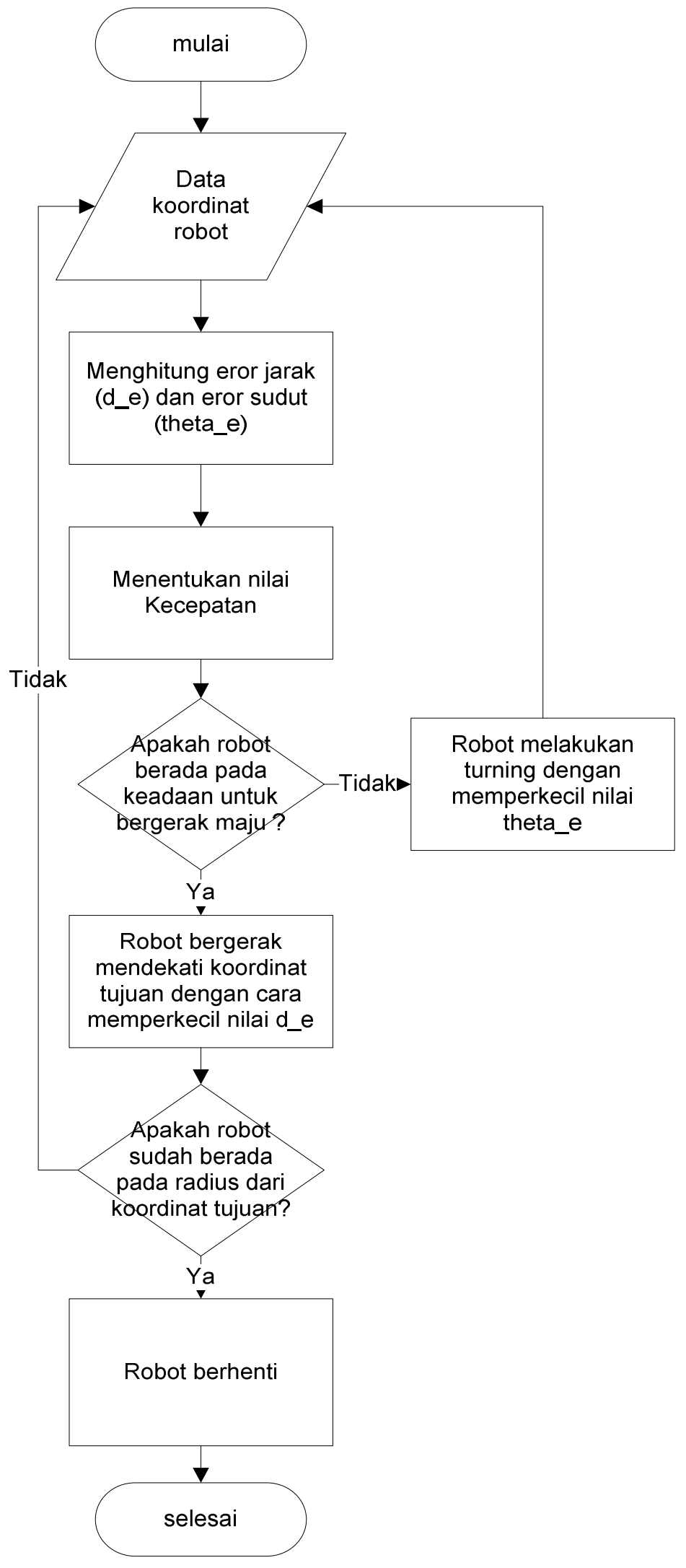

Gambar 2.Flowchart Fungsi Posisi Satu Muka 


\subsection{Flowchart Fungsi Posisi Dua Muka}

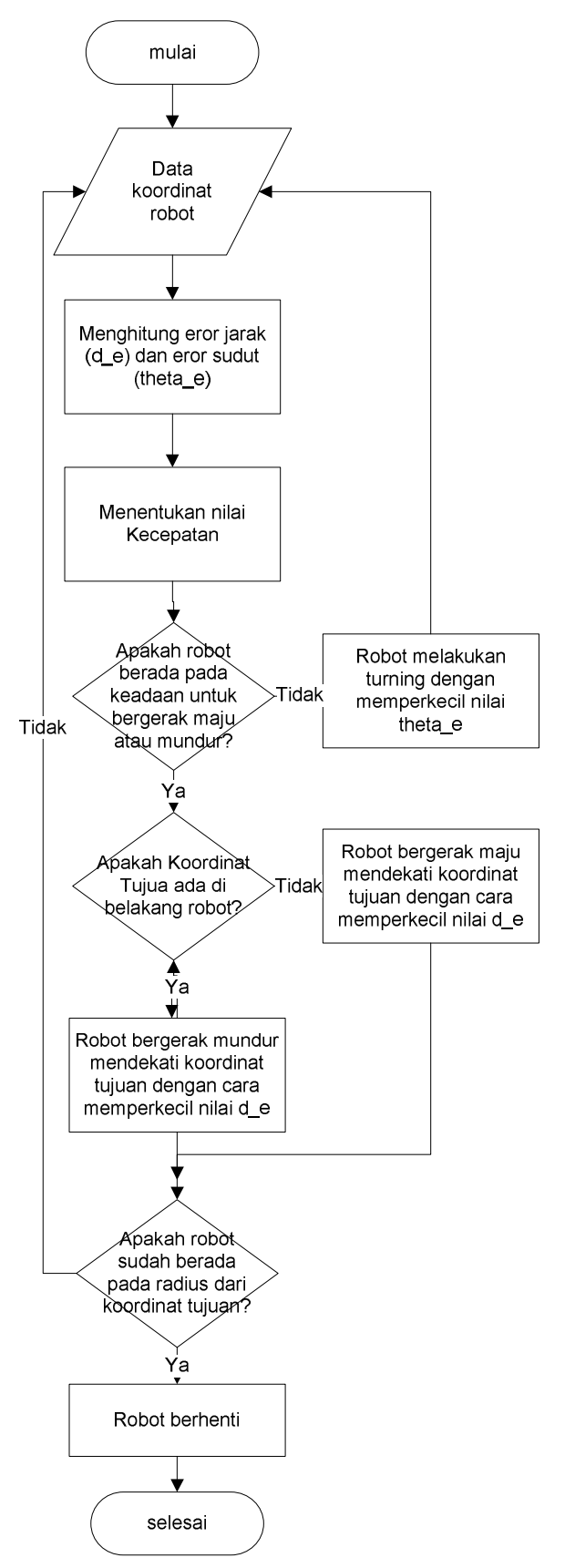

Gambar 3.Flowchart Fungsi Posisi Dua Muka

Fungsi posisi dua muka mempunyai perbedaan dengan fungsi posisi satu muka, yaitu dalam hal penggunaan di strategi. Apabila fungsi posisi satu muka kebanyakan digunakan untuk strategi menyerang, fungsi posisi dua muka kebanyakan digunakan untuk strategi bertahan. Contoh pemanfaatan fungsi posisi dua muka adalah untuk saat goalkeeper harus memblok bola maka, robot goal keeper tidak harus memutar tetapi mengganti wajah dari belakang menjadi depan, karena saat saat memutar akan membutuhkan lebih waktu lebih lama jika di bandingkan dengan mengganti posisi muka.Flowchart fungsi posisi dua muka dapat dilihat pada Gambar 3. Pada saat perintah diberikan pada robot untuk berhenti maka velocity = 0 . Ketika robot pergi ke bola maka velocity akan disesuaikan dengan jarak dan sudut dari posisi tujuan. 


\section{HASIL DAN PEMBAHASAN}

Fungsi posisi yang dibuat mempunyai kecepatan yang berbeda-beda, kecepatan dari robot ditentukan berdasarkan eror jarak dan eror sudut antara posisi robot dengan posisi tujuan.Data kecepatan yang dikirim ke robot berdasarkan eror jarak dapat dilihat pada tabel 1. Selain berdasarkan eror jarak, kecepatan robot juga dipengaruhi oleh eror sudut. Untuk eror sudut yang besar diperlukan kecepatan yang rendah hal tersebut ditujukan agar tidak sering terjadi slip. Kecepatan yang dikirim pada eror sudut lebih besar dari 40 derajat adalah $50 \mathrm{~cm} / \mathrm{s}$. Sedangkan untuk memperpendek jarak tempuh robot memerlukan pergerakan memutar yaitu pada eror sudut lebih besar dari 65 derajat dan lebih kecil dari -65 derajat.

Tabel 1. Data Kecepatan yang dikirim ke robot berdasarkan eror jarak

\begin{tabular}{|c|c|}
\hline $\begin{array}{c}\text { eror jarak } \\
(\mathbf{c m})\end{array}$ & $\begin{array}{c}\text { kecepatan } \\
\text { (cm/s) }\end{array}$ \\
\hline$<=4$ & 0 \\
\hline $4-30$ & 35 \\
\hline $31-40$ & 50 \\
\hline $41-80$ & 80 \\
\hline $81-100$ & 100 \\
\hline$>=100$ & 120 \\
\hline
\end{tabular}

Pengujian dilakukan dengan membandingkan dengan fungsi posisi yang dikembangkan Prof. Kim et al. 2014. Data yang diambil dalam pengujian adalah waktu, jarak dan sudut. Jarak dan sudut terhadap bola yang diujikan diambil data waktu dan dibuat rata-rata. Jarak diambil mulai dari 20-200 dengan satuan $\mathrm{cm}$ dan sudut diambil mulai dari 0-90 derajat. Dari hasil pengujian fungsi posisi didapatkan tabel yang berisi data kecepatan (detik) dan jarak $(\mathrm{cm})$ dari pengujian fungsi posisi yang dikembangkan Kim et al., 2004 dan fungsi posisi dari hasil penelitian.Data pengujian dapat dilihat pada tabel 2. Setelah dibuat tabel data hasil pengujian akan dibuat grafik perbandingan. Grafik perbandingan fungsi posisi dapat dilihat pada Gambar 4-7.

Tabel 2. Data Kecepatan (detik) dari Pengujian Fungsi Posisi

\begin{tabular}{|c|c|c|c|c|c|c|c|c|}
\hline \multirow{3}{*}{ 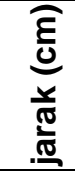 } & \multicolumn{8}{|c|}{ SUDUT (derajat) } \\
\hline & \multicolumn{2}{|c|}{0} & \multicolumn{2}{|c|}{30} & \multicolumn{2}{|c|}{60} & \multicolumn{2}{|c|}{90} \\
\hline & $\mathbf{K}$ & $\mathbf{P}$ & K & $\mathbf{P}$ & K & $\mathbf{P}$ & K & $\mathbf{P}$ \\
\hline 20 & 1,3 & 1,2 & 1,4 & 1,5 & 2,4 & 1,4 & 1,6 & 1,7 \\
\hline 40 & 3,1 & 1,8 & 2,5 & 2,4 & 2,8 & 2,2 & 2,5 & 2,3 \\
\hline 60 & 2,7 & 2,1 & 3,0 & 2,6 & 3,1 & 2,6 & 3,4 & 2,8 \\
\hline 80 & 3,7 & 2,9 & 3,5 & 2,9 & 3,3 & 3,0 & 3,4 & 3,1 \\
\hline 100 & 3,8 & 3,0 & 4,7 & 3,0 & 4,0 & 3,2 & 4,4 & 3,2 \\
\hline 120 & 4,7 & 3,1 & 5,5 & 3,9 & 6,0 & 3,1 & 6,0 & 3,5 \\
\hline 140 & 4,5 & 3,1 & 4,5 & 3,6 & 4,6 & 3,8 & 4,6 & 3,5 \\
\hline 160 & 4,9 & 3,6 & 5,0 & 3,9 & 5,3 & 4,0 & 5,2 & 4,1 \\
\hline 180 & 5,5 & 3,8 & 5,5 & 3,6 & 5,6 & 3,8 & 5,9 & 4,2 \\
\hline 200 & 6,0 & 4,2 & 6,1 & 4,1 & 6,2 & 4,4 & 6,3 & 4,4 \\
\hline
\end{tabular}




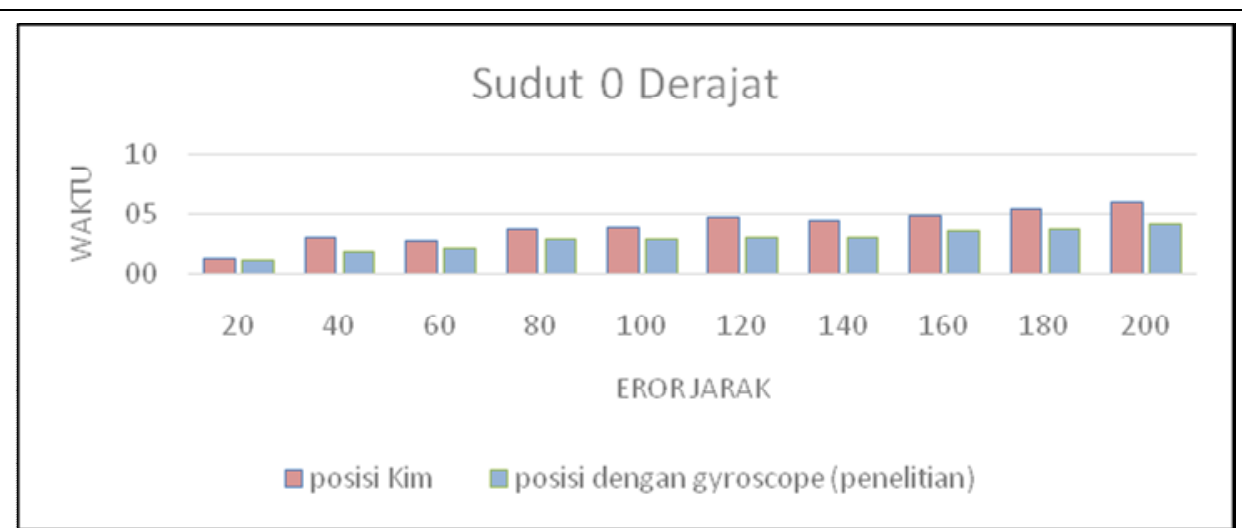

Gambar 4. Grafik Perbandingan Fungsi Posisi Sudut 0 Derajat

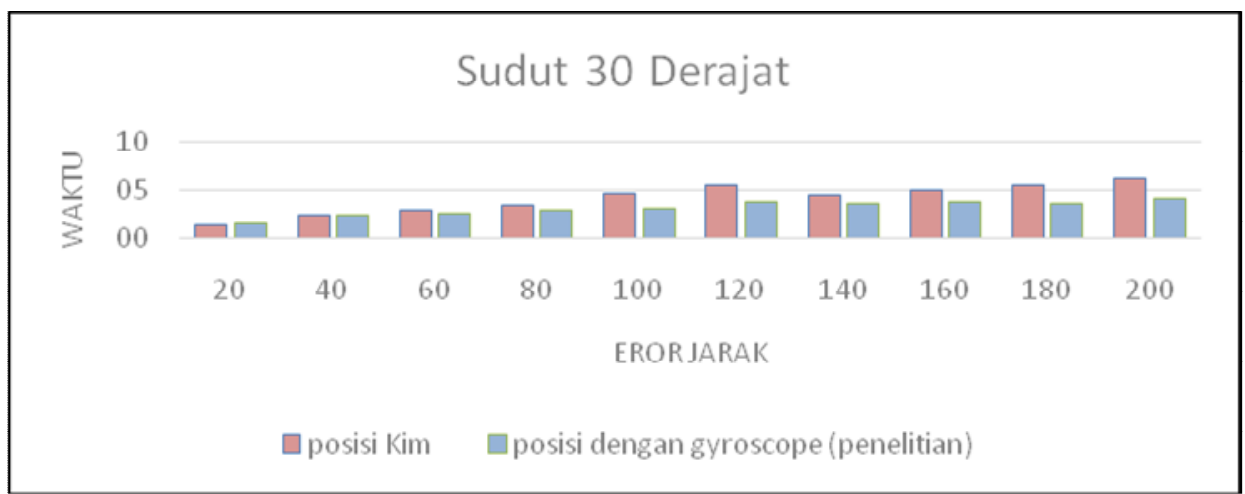

Gambar 5. Grafik Perbandingan Fungsi Posisi Sudut 30 Derajat

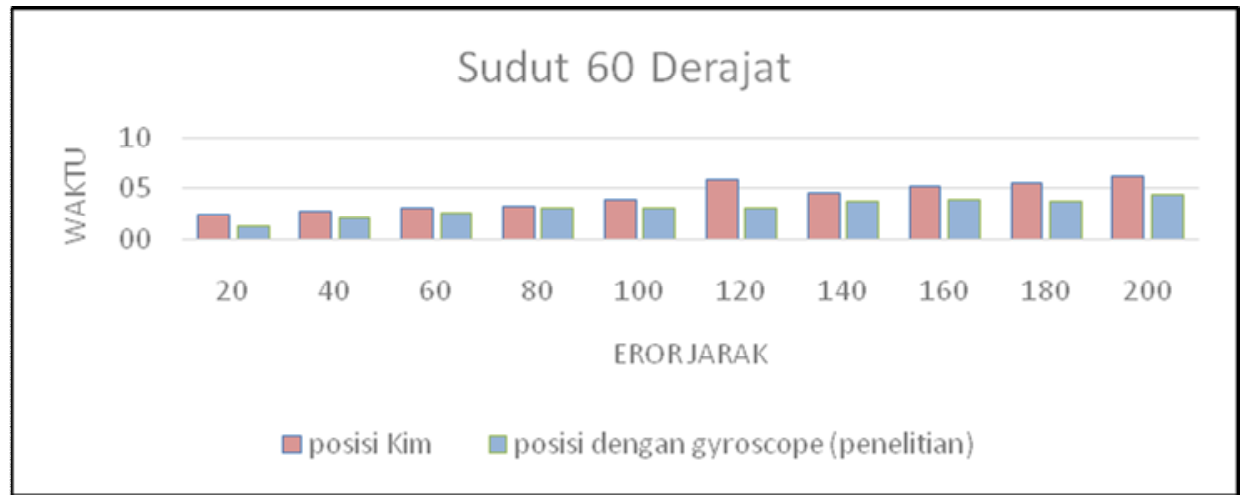

Gambar 6. Grafik Perbandingan Fungsi Posisi Sudut 60 Derajat

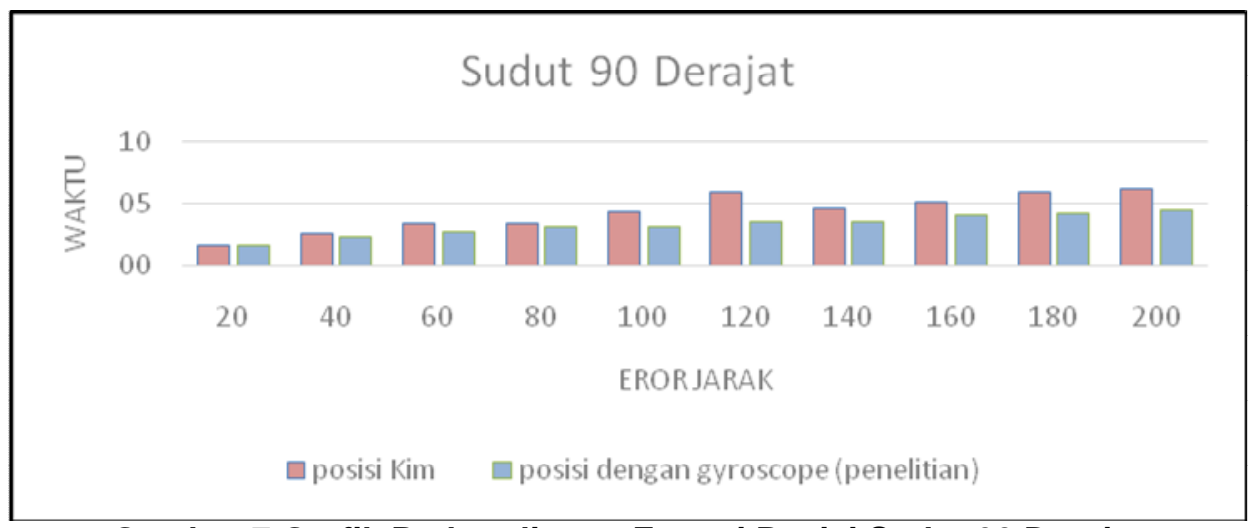

Gambar 7.Grafik Perbandingan Fungsi Posisi Sudut 90 Derajat 
Berdasarkan grafik diatas dapat diperoleh bahwa fungsi posisi yang paling cepat pada setiap kondisi sudut dan jarak adalah fungsi posisi menggunakan yang memperhatikan nilai sensor gyroscope, kecuali pada eror sudut 30 derajat dengan eror jarak $20 \mathrm{~cm}$, eror sudut 30 derajat dengan eror jarak $40 \mathrm{~cm}$ dan eror sudut 90 derajat dengan eror jarak $20 \mathrm{~cm}$.

\section{KESIMPULAN}

Berdasarkan dari hasil analisis, perancangan dan implementasi yang telah dilakukan sebelumnya, maka dapat diambil beberapa kesimpulan, antara lain:

1. Telah dihasilkan fungsi posisi untuk bergerak sampai keposisi tujuan dengan cepat dan tepat sesuai dengan karakter dari robot MiroSot UPN "Veteran" Yogyakarta.

2. Fungsi posisi tanpa menggunakan sensor gyroscope mempunyai kecepatan maksimal pada eror jarak lebih dari $100 \mathrm{~cm}$, yaitu dengan kecepatan $70 \mathrm{~cm} / \mathrm{s}$, lebih besar jika dibandingkan dengan fungsi positioning yang dikembangkan oleh Kim et al., 2004 yaitu 55 $\mathrm{cm} / \mathrm{s}$. Fungsi posisi dengan menggunakan sensor gyroscope mempunyai kecepatan maksimal pada eror jarak lebih dari $100 \mathrm{~cm}$, yaitu dengan kecepatan $120 \mathrm{~cm} / \mathrm{s}$, lebih besar jika dibandingkan dengan fungsi positioning yang dikembangkan oleh Kim et al., 2004 dan fungsi posisi tanpa menggunakan sensor gyroscope.

3. Dari hasil pengujian, dapat disimpulkan bahwa fungsi posisi dengan sensor gyroscope lebih cepat sampai ketujuan dibandingkan dengan fungsi posisi tanpa sensor gyroscope dan fungsi posisi yang dikembangkan oleh Prof Kim et al., 2004..

\section{DAFTAR PUSTAKA}

Baltes, J., McGrath, S., dan Anderson, J. 2004. The Use of Gyroscope Feedback in the Control of the Walking Gatis for a Small Humanoid Robot. Departement of Computer Science University of Manitoba Winnipeg, Canada.

Benhabib, B. 2008. Robot Soccer Strategy. Department of Mechanical and Industrial Engineering University of Toronto.Canada.

Choi, S.H., Kim, J.H., Kim, Y.H., dan Park, I.W.2009. Evolutionary Multi-Objective Optimization in Robot Soccer System for Education. 1556-603X/09/\$25.00@2009IEEE. KAIST, Republik of Korea.

FIRA.2014. FIRAMiroSot Game Rules for Middle League and Large League. http://fira.net/contents/sub03/sub03 3asp. Diakses pada 19 Maret 2014.

Gang, M., Liu, T. S., Han, J.X. dan Wang, X.X. 2010. The Color Tag Design and Color Model Study in Mirosot. School of Computer Science, Xi'an Shiyou University,Xi'an, China.

Guerchouche, R. dan Coldefy, F. 2007. Camera Calibration Methods Evaluation Procedure for Images Rectification and $3 D$ Reconstruction. Orange Labs - France Telecom R\&D, TECH/IRIS/VIA, 2, Av. Pierre Marzin, France 22307, Lannion Cedex.

Han, K.H, Lee, K.H., Moon, C.K., Lee, H.B., dan Kim J.H. 2002. Robot Soccer System of SOTY 5 for Middle League MiroSot. Department of Electrical Engineering and Computer Science, Korea Advanced Institute of Science and Technology (KAIST).Guseong-dong.

Huabin, A., Lei, W., dan Zengqi, S.2004. Accurate and Stable Vision in Robot Soccer. Department of Computer Science and Technology, Tsinghua University, Beijing.

Kim, K.H., Ko, K.W., Kim, J.G., Lee, S.H. dan Cho, HS. 1997. The Development of a Micro Robot System for Robot Soccer Game, International Conference on Robotics and Automation, Albuquerque, New Mexico.

Li, J., Han, X., Xu, X. dan Li, Y. 2004. An Approach of Color Object Searching for Vision System of Soccer Robot. Proceedings of the 2004 IEEE, International Conference on Robotics and Biomimetics. China. 
Miranda, J.L.C. 2009. Aplication Of Kalman Filtering and PID Control for Direct Interved Pendulum Control, A Project, Presented,to the Faculty of California State University, Chico, Spring.

Pana, C.F., Nicu, G.B, lonut, C.R., dan Marius, N. 2008. Strategy Panning for MiroSot Soccer's Robot. 8th WSEAS International Conference on APPLIED INFORMATICS AND COMMUNICATIONS (AIC'08). Rhodes, Greece.

Simancas A.E., 2004. Modelización con Ecosimpro: Robosot.

Trusov, A. A. 2011. Overview of MEMS Gyroscopes: History, Principles of Operations, Types of Measurements. Irvine, California, USA.

Vieira, F.C., Alsina, P.J. dan Medeiros, A.A.D. 2011. Micro-Robot Soccer Team - Mechanical And Hardware Implementation. DCA - CT - Universidade Federal do Rio Grande do Norte, Campus Universitário - Lagoa Nova - 59072-970 - Natal.

Wang, Y. M., Li, Y. dan Zheng, B. 2010. A Camera Calibration Technique Based on OpenCV, College of Infonnatics \& Electronics,Zhejiang Sci-Tech University,Hangzhou, China. 